\title{
Social Security Policy with Public Debt in an Aging
}

\section{Economy*}

\author{
By Tetsuo Ono ${ }^{\dagger}$
}

\begin{abstract}
This paper analyzes a social security policy with public debt in an overlapping generations growth model. In particular, the paper considers a situation in which population aging causes a heavy burden of social security payments where public debt is issued by the government to finance the payment. In the model presented below, an economy with an aging population may achieve two dynamically inefficient equilibria. Under certain conditions, the effects of pension reform and population aging on capital accumulation are entirely different between the two equilibria.
\end{abstract}

Keywords: Population aging, Social security, Pension reform, Public debt, Economic growth, Overlapping generations.

JEL Classification: D91, E62, H55, H63.

${ }^{*}$ I am grateful to Kazuyo Tanimoto and Kiheiji Nishida for their research assistance. The research reported here was conducted as part of a larger study, the "Project on Intergenerational Equity" at the Institute of Economic Research, Hitotsubashi University. Financial support from Kani Hoken Bunka Zaidan is also gratefully acknowledged.

${ }^{\dagger}$ Correspondence to: Tetsuo Ono, Institute of Policy and Planning Sciences, University of Tsukuba, 1-1-1, Tennoudai, Tsukuba, Ibaraki 305-8573, Japan. e-mail: ono@sk.tsukuba.ac.jp 


\section{Introduction}

This paper develops an overlapping generations model of growth and aging according to the model suggested by Pecchenino and Pollard (1997), and then uses this framework to analyze the economic impact of social security financed by public debt. The situation considered here is that an aging population leads to a heavy burden of public pension payments, where social security tax alone would not be sufficient to fully finance such payments. Public debt is introduced in order to supplement this balance, and its effects on capital accumulation and dynamic efficiency are considered. Furthermore, the economic impact of social security reform and population aging will also be examined.

The present analysis is motivated by two important issues in Japan, namely, population aging and government budget deficits. Since the Japanese public pension scheme is based on a pay-asyou-go scheme, population aging leads to a greater burden of social security payments on younger members of society. ${ }^{1}$ In addition, since the payments are partly funded by the state budget, government deficits and social security finance are closely related to each other. Therefore, this paper implements the analysis of social security and government deficits (i.e., public debt) in an economic environment that includes population aging.

The present analysis is also motivated by a proposal suggested by several Japanese economists, namely, a shift from a pay-as-you-go scheme to an actuarially fair pension scheme in preparation for the effects of population aging (see, for example, Hatta and Oguchi (1992)). Such a reform might be capable of solving the problem of increasing social security payments, but it causes yet another problem: who bears the burden of the social security payments owed to an existing older generation? If the economy introduces an actuarially fair pension scheme to a currently

\footnotetext{
1 The Japanese public pension system originally started as an actuarially fair scheme. However, the payments to older people has been largely financed by social security tax revenue from the younger generation. The system is therefore approximately the same as a pay-as-you-go scheme.
} 
younger generations and to all subsequent generations, the currently older generation cannot receive payments from the currently younger generation. In order to solve this new problem, many economists in Japan have proposed that the payments to the currently older generation should be financed by public debt. This paper considers the effectiveness of this policy in terms of dynamic efficiency.

Several studies have analyzed public pension and population aging in economic growth models (e.g., Meijdam and Verbon (1997), Pecchenino and Pollard (1997), Pecchenino and Utendorf (1999), and Futagami and Nakajima $\left.(2001)^{2}\right)$. However, these studies do not consider a social security policy together with public debt. Gertler (1997), who modified the Blanchard (1985) and Weil (1989) framework in order to allow life-cycle behavior, analyzed social security as financed by public debt. However, his study assumed a perfect annuity market, and the analysis was therefore unable to capture the economic impact of a pension reform toward an actuarially fair scheme.

This paper attempts to analyze social security policy with public debt under conditions of imperfect annuity, a topic which has not been fully addressed in previous studies but nevertheless is more likely to reflect the real world. The present paper utilizes the model of Pecchenino and Pollard (1997), and introduce public debt into their model. The present paper considers pension reform and shows its effects on capital accumulation and dynamic efficiency in equilibrium. The present analysis would therefore aid policy-makers in Japan as well as those in industrialized countries who are running budget deficits against the background of a heavy burden of social security payments caused by an aging population.

The main findings of the present analysis are as follows. First, when an economy with an

\footnotetext{
2 They analyzed the economic effects of demographic structure in the presence of a social security system. In contrast, Bental (1989), Raut (1992), Cigno (1993), Zhang and Nishimura (1993), Zhang (1995), and Zhang and Zhang (1995) examined the impact of social security on fertility rate. The present paper focuses on the former effect, and we assume that fertility rate is an exogenous parameter.
} 
aging population is heavily burdened with social security payments and the government issues public debt to finance payments, the economy experiences a dynamically inefficient equilibrium characterized by excessive savings, i.e., overaccumulation of capital. In particular, there may be two dynamically inefficient steady state equilibria: one is a saddle with a lower stock of capital, and the other is a sink with a higher stock of capital. The former is relatively efficient compared to the latter, but the economy would converge to the latter under most initial conditions. Second, comparative statics analyses depend heavily on whether the economy attains the former or the latter equilibrium. Under certain conditions, the effects of pension reform and population aging on economic growth are entirely different between the two equilibria.

This paper is organized as follows: Section 2 develops the model. Section 3 characterizes social optimum. Section 4 characterizes a competitive equilibrium and analyzes the existence, uniqueness, and stability of that equilibrium. Section 5 undertakes a comparative statics analysis. Section 6 weighs the consequences of a social security policy under an alternative assumption. Section 7 discusses the implications of a social security policy with public debt in an aging economy.

\section{The Model}

The present model is based on that developed by Pecchenino and Pollard (1997). Consider an infinite-horizon economy composed of identical agents, perfectly competitive firms, annuity markets, and a government. A new generation, called generation $t$, is born in each period $t=1,2,3, \ldots$. Generation $t$ is composed of a continuum of $N_{t}>0$ units of identical agents. Assuming that $N_{t}=(1+n) N_{t-1}$ : the net rate of population growth is $n>-1$.

Agents in this economy are non-altruistic: the old do not care for the young and the young do not care for the old. Agents live at a maximum of two periods, youth and old age. An agent 
dies at the beginning of old age with a probability of $1-p$ and lives throughout old age with a probability of $p \in(0,1]$. If an agent dies young, his annuitized wealth is transferred to the agents who live throughout old age, and his unannuitized wealth is bequeathed to his children as unintentional bequests.

In youth, each agent is endowed with one unit of labor, which is supplied inelastically to firms, and each agent obtains wages. An agent in generation $t$ divides his wage $w_{t}$ between his own current consumption $c_{t}^{1}$, saving (held either as an annuity, as direct holdings of capital and public debt, or both) for consumption in old age $s_{t}$, and the payment of social security taxes quoted as a proportion of his wage $\tau^{w} w_{t} ; \tau^{w}$ is the rate of social security tax levied on wage income. Thus, the budget constraint for a young agent in generation $t$ is:

$$
c_{t}^{1}+s_{t}=\left(1-\tau^{w}\right) w_{t}+I_{t}
$$

where $I_{t}$ is the per capita bequest from generation $t-1$ to generation $t$.

In old age, agents supply their savings inelastically to firms and consume the return and their social security benefits. Actuarially fair annuity contracts are assumed to be unavailable in the private market. The government overcomes this market failure by establishing a market in actuarially fair annuity contracts, whereby it can control access in the following way: each agent may place up to a ratio of $\gamma \in[0,1]$ of his total savings in an annuity. ${ }^{3}$

The budget constraint for generation $t$ in old age is:

$$
c_{t+1}^{2}=\left(1+r_{t+1}+\alpha_{t+1}\right) s_{t}+\tau^{l}
$$

where $c_{t+1}^{2}$ is consumption in old age and $\tau^{l}$ is social security benefits. ${ }^{4}$ The return on savings

\footnotetext{
3 This is a voluntary plan accroding to Pecchenino and Pollard (1997). They also have considered another plan, i.e., a mandatory plan in which each agent must place a part of his fixed amount of income in an annuity. This paper adopts only the voluntary plan and clarifies the difference between a perfect annuity $(\gamma=1)$ and an imperfect annuity $(\gamma<1)$.

${ }^{4}$ In the real world, there are two forms of social security payments. One is a lump sum transfer and the other
} 
in (2) is stated as the sum of the return of direct holdings of capital, $1+r_{t+1}$, and the excess return, prorated over all savings, of holding a ratio, $\gamma$, of savings as an annuity, $\alpha_{t+1}$. Agents without bequest motives would prefer to annuitize all their wealth to the level just under the legal restriction.

If an agent dies young, then the unannuitized portion of his wealth,

$$
N_{t+1} I_{t+1}=N_{t}(1-\gamma)(1-p)\left(1+r_{t+1}\right) s_{t}
$$

is distributed to his heirs, where $(1-\gamma)$ is the ratio of wealth not annuitized. The annuitized portion is distributed among the other holders of annuities:

$$
p \alpha_{t+1} s_{t}=\gamma(1-p)\left(1+r_{t+1}\right) s_{t}
$$

Under budget constraints (1) and (2), the utility maximization problem of an agent in generation $t$ is to maximize $\ln c_{t}^{1}+p \ln c_{t+1}^{2}$ subject to budget constraints (1) and (2), where $w_{t}, r_{t+1}$, $\alpha_{t+1}, \tau^{w}$, and $\tau^{l}$ are given. Solving the problem leads to the following saving function:

$$
s_{t}=\frac{p}{1+p}\left\{\left(1-\tau^{w}\right) w_{t}+I_{t}\right\}-\frac{\tau^{l}}{(1+p)\left(1+r_{t+1}+\alpha_{t+1}\right)} .
$$

This saving function states that a higher level of wage or bequest implies higher savings, whereas a higher level of social security benefits implies lower savings. A higher rate of interest leads to a lower value of social security benefits evaluated in youth, thus enhancing savings. ${ }^{5}$

The government in this particular economy can impose a social security tax, $\tau^{w}$, on wages. Moreover, it can issue public debt with a one-period maturity in order to finance social security payments. The government funds the expenditure of social security and the repayment of the is a transfer based on a replacement rate on wages. Following Pecchenino and Pollard (1997), this paper adopts the former scheme in order to simplify the analysis. Section 6 briefly considers an economy operating with the latter form of payments.

${ }^{5}$ It should be noted that the saving function (5) is the outcome of a partial equilibrium. Thus, the effects of wage, social security benefits, and interest rate on saving, found in (5), are not necessarily observed in a general equilibrium. 
debt with tax receipts and with the revenue from the newly issued debt. Thus, the government budget constraint in period $t$ is $B_{t+1}+N_{t} \tau^{w} w_{t}=R_{t} B_{t}+p N_{t-1} \tau^{l}$, where $B_{t}$ is the value of public debt maturing during period $t$, and $R_{t}$ is the gross rate of return. As regards the left-hand side of the above constraint, $B_{t+1}$ is the revenue from debt issue, while $N_{t} \tau^{w} w_{t}$ is the revenue from social security tax. As regards the right-hand side, $R_{t} B_{t}$ is the repayment of debt, whereas $p N_{t-1} \tau^{l}$ represents the social security payments. Dividing both sides by $N_{t}$ leads to the following equation:

$$
(1+n) b_{t+1}+\tau^{w} w_{t}=R_{t} b_{t}+\frac{p}{1+n} \tau^{l}
$$

where $b_{t} \equiv B_{t} / N_{t}$ is public debt per worker in period $t$. If $\tau^{w} w_{t}<p \tau^{l} /(1+n)$, then the economy experiences an excess burden of social security payments; that is, the social security payments are not fully financed by the social security tax revenues. The government therefore supplements this balance by issuing public debt.

Firms are considered as perfectly competitive profit maximizers that produce output using the standard neoclassical production function $Y_{t}=F\left(K_{t}, L_{t}\right)$, where $Y_{t}$ is aggregate output, $K_{t}$ is aggregate capital, and $L_{t}$ is aggregate labor. ${ }^{6}$ The production function can be rewritten in an intensive form as $y_{t}=f\left(k_{t}\right)$, where $k_{t} \equiv K_{t} / L_{t}$ is a per capita capital stock in period $t$. Capital depreciates at the rate of $\delta \in[0,1]$. We assume the following with respect to the intensive form of the production function, which holds in the case of the Cobb=Douglas functions. ${ }^{7}$

Assumption 1: The intensive form of the production function $f(\cdot): \Re_{+} \rightarrow \Re_{+}$is continuous, strictly increasing and strictly concave on $\Re_{+}$and twice continuously differentiable on $\Re_{++}$ with the following constraints:

\footnotetext{
${ }^{6} L_{t}=N_{t}$ for all $t$ because of the inelastic labor supply of young agents.

7 Contrary to Pecchenino and Pollard (1997) who assumed the production function with external effects of aggregate capital à la Romer (1986), the present paper adopts a standard neoclassical production function. This is because the golden rule (defined in Section 3) is used as a measure of dynamic efficiency.
} 
(i) $f(0)=0, \lim _{k \rightarrow 0} f^{\prime}(k)=\infty$, and $\lim _{k \rightarrow \infty} f^{\prime}(k)=0$;

(ii) $f^{\prime}(k) k$ is increasing in $k$.

First-order conditions for profit maximization are as follows:

$$
\left\{\begin{array}{c}
w_{t}=f\left(k_{t}\right)-k_{t} f^{\prime}\left(k_{t}\right) \equiv w\left(k_{t}\right), \\
\rho_{t}=f^{\prime}\left(k_{t}\right) \equiv \rho\left(k_{t}\right)
\end{array}\right.
$$

where $\rho_{t}$ is the rental price of capital in period $t$. Due to the assumed condition of perfect competition, these conditions imply factor markets clearing.

A market clearing condition for capital is $K_{t+1}+B_{t+1}=N_{t} s_{t}$, which expresses the equality of the total savings by young agents in generation $t, N_{t} s_{t}$, to the sum of the stocks of aggregate physical capital and aggregate public debt. Dividing both sides by $N_{t}$ leads to

$$
(1+n)\left(k_{t+1}+b_{t+1}\right)=s_{t}
$$

Since the market for capital is competitive, the following arbitrage condition holds:

$$
R_{t+1} \equiv 1+r_{t+1}=1-\delta+\rho_{t+1}
$$

In period 1, there are both young agents in generation 1 and initial old agents in generation 0. Each agent in generation 0 is endowed with $k_{1}$ units of capital, earns the return $\left(1+r_{1}+\alpha_{1}\right) k_{1}$, and consumes it. The measure of the initial old agents is $p N_{0}>0$. The utility of an agent in generation 0 is $\ln c_{1}^{2}$.

\section{Social Optimum}

Before analyzing the laissez-faire behavior of agents and firms, we focus our attention on socially optimal allocation. Following Azariadis (1993), this paper adopts quasi-stationary allocations of 
the form

$$
C=\left(\begin{array}{c}
c_{1}^{2} \\
c^{1} \\
c^{2}
\end{array}\right)
$$

which treats agents in an identical manner irrespective of the generation to which they belong. The only exception is the special generation 0 , which receives special treatment in matrix $C$. The top row, $c_{1}^{2}$, is the consumption by generation 0 ; the middle row, $c^{1}$, is the consumption by generation $t \geq 1$ in youth; and the bottom row, $c^{2}$, is the consumption by generation $t \geq 1$ in old age.

Definition 1: A feasible quasi-stationary allocation is the social optimum if (i) it treats identical agents in the same way; (ii) there is no other feasible quasi-stationary allocation that improves the economic status of at least one agent without reducing the status of any other agent.

Socially optimal allocations maximize the social welfare function $\lambda p \ln c_{1}^{2}+\ln c^{1}+p \ln c^{2}$, which is subject to the following feasibility constraints:

$$
\begin{aligned}
\frac{p}{1+n} c_{1}^{2}+c^{1}+(1+n) k & =f\left(k_{1}\right)+(1-\delta) k_{1}, \\
\frac{p}{1+n} c^{2}+c^{1}+(1+n) k & =f(k)+(1-\delta) k,
\end{aligned}
$$

where $\lambda>0$ is the relative weight given to generation 0 . The first equation is the resource constraint in period 1 , and the second equation is the resource constraint in period $t \geq 2$.

Solving this problem leads to the following equation:

$$
1-\delta+f^{\prime}(k) \geq 1+n
$$

with equality maintained as long as generation 0 carries no weight in the social welfare function. The outcome, $k^{*}$, equalizes the net marginal product of capital to the growth rate, $f^{\prime}\left(k^{*}\right)=\delta+n$. 
Following the conventional terminology, we refer to $k^{*}$ as the golden rule. If the steady state level of capital $k$ satisfies $k<(>) k^{*}$, then the economy is dynamically efficient (inefficient). The analysis below uses the golden rule to judge the efficiency of equilibrium.

\section{Competitive Equilibrium}

Definition 2: A competitive equilibrium is a sequence of prices $\left\{w_{t}, \rho_{t}, \alpha_{t}, r_{t}\right\}_{t=1}^{\infty}$, a sequence of allocations $\left\{c_{t}^{1}, c_{t}^{2}\right\}_{t=1}^{\infty}$, and a sequence of capital stock $\left\{k_{t}\right\}_{t=1}^{\infty}$ and public debt $\left\{b_{t}\right\}_{t=1}^{\infty}$ with the initial condition $\left(k_{1}, b_{1}\right)$ and exogenous parameters $\left\{p, n, \tau^{w}, \tau^{l}\right\}$, such that given these prices and allocations, an agent's utility is maximized, firms' profits are maximized, the government budget constraint is satisfied, and markets clear.

This section characterizes the competitive equilibrium allocation of capital and debt $\left\{k_{t}, b_{t}\right\}$. Then, it examines the existence of the equilibrium and its dynamic efficiency. Finally, the stability of the equilibrium is considered.

\subsection{Characterization of the Competitive Equilibrium}

Summarizing (1) - (9), the competitive equilibrium is fully characterized by a sequence $\left\{k_{t}, b_{t}\right\}_{t=1}^{\infty}$ with the initial condition $\left(k_{1}, b_{1}\right)$, such that the sequence satisfies the following two equations:

$$
\begin{aligned}
(1+n)\left(k_{t+1}+b_{t+1}\right)= & \frac{p}{1+p}\left\{\left(1-\tau^{w}\right) w\left(k_{t}\right)+(1-\gamma)(1-p) R\left(k_{t}\right)\left(k_{t}+b_{t}\right)\right\} \\
& -\frac{\tau^{l}}{(1+p) R\left(k_{t+1}\right)\left(1+\frac{\gamma(1-p)}{p}\right)}, \\
(1+n) b_{t+1}+\tau^{w} w\left(k_{t}\right)= & R\left(k_{t}\right) b_{t}+\frac{p}{1+n} \tau^{l} .
\end{aligned}
$$

Eq. (10) is derived from the saving function (5) and the market clearing condition for capital (8). Eq. (11) is a rewrite of the government budget constraint. Substitution of $b_{t+1}$ from (11) to 
(10) leads to the following equation:

$$
\begin{aligned}
& (1+n) k_{t+1}+\frac{\tau^{l}}{(1+p) R\left(k_{t+1}\right)\left(1+\frac{\gamma}{p}(1-p)\right)} \\
= & \frac{p}{1+p}\left\{\left(1-\tau^{w}\right) w\left(k_{t}\right)+(1-\gamma)(1-p) R\left(k_{t}\right)\left(k_{t}+b_{t}\right)\right\}-\left\{R\left(k_{t}\right) b_{t}+\frac{p}{1+n} \tau^{l}-\tau^{w} w\left(k_{t}\right)\right\} .
\end{aligned}
$$

Eqs. (11) and (12) constitute a planar system of $(k, b)$.

We proceed with our analysis of the equilibrium using a phase diagram. We initially draw the phase diagram by which (12) yields the following equation:

$$
\begin{aligned}
& k_{t+1} \geqslant k_{t} \Leftrightarrow b_{t} \leqslant G\left(k_{t}\right) \equiv \frac{\frac{p}{1+p}\left\{\left(1-\tau^{w}\right) w\left(k_{t}\right)+(1-\gamma)(1-p) R\left(k_{t}\right) k_{t}\right\}}{\left\{1-\frac{p}{1+p}(1-\gamma)(1-p)\right\} R\left(k_{t}\right)} \\
& +\frac{-\frac{p}{1+n} \tau^{l}+\tau^{w} w\left(k_{t}\right)-(1+n) k_{t}-\frac{\tau^{l}}{(1+p) R\left(k_{t}\right)\left(1+\frac{\gamma(1-p)}{p}\right)}}{\left\{1-\frac{p}{1+p}(1-\gamma)(1-p)\right\} R\left(k_{t}\right)} .
\end{aligned}
$$

Figure 1 depicts the graph of $G(\cdot)$ and the motion of $k .^{8}$

We can now draw the phase diagram by which (11) yields

$$
b_{t+1} \geqslant b_{t} \Leftrightarrow b_{t} \gtrless H\left(k_{t}\right) \equiv \frac{\frac{p}{1+n} \tau^{l}-\tau^{w} w\left(k_{t}\right)}{1+n-R\left(k_{t}\right)} \quad \text { if } k_{t} \lessgtr k^{*},
$$

where $k^{*}=k^{*}(\delta, n)$, i.e., the golden rule: $f^{\prime}\left(k^{*}\right)=\delta+n$ (see previous section). Moreover, $k^{* *}=k^{* *}\left(p, n, \tau^{l}, \tau^{w}\right)$, which is defined as $p \tau^{l} /(1+n)=\tau^{w} w\left(k^{* *}\right) .{ }^{9}$ If $k=k^{* *}$, then $H(k)=b=0$ holds true. The phase diagrams are depicted in Figure 2. In particular, Figure 2a (2b) shows the case of $k^{*}<(>) k^{* *}$.

Whether $k^{*}$ is greater than or less than $k^{* *}$ depends on parameters $p, \tau^{l}, \tau^{w}$, and $n$. The inequality $k^{*}<(>) k^{* *}$ holds if the economy has higher (lower) $p$ and $\tau^{l}$ and a lower (higher) $\tau^{w}$.

\footnotetext{
${ }^{8}$ Figure 1 is a rough sketch of the function $G(\cdot)$. In Subsection 4.2, the property of $G(\cdot)$ is defined in order to show the existence of the equilibrium.

${ }^{9}$ The notation $k^{*}(\delta, n)$ implies that $k^{*}$ depends on parameters $\delta$ and $n$, whereas $k^{* *}\left(p, n, \tau^{l}, \tau^{w}\right)$ indicates that $k^{* *}$ depends on $p, n, \tau^{l}$, and $\tau^{w}$.
} 
In other words, $k^{*}<(>) k^{* *}$ holds if the economy has higher (lower) longevity, a larger (smaller) amount of per capita social security payments, and a lower (higher) rate of social security tax. If $k^{*}<k^{* *}$ holds, the economy is faced with both an aging population and a heavy social security burden. As regards the rate of population growth, a higher $n$ implies a lower $k^{*}$ and $k^{* *}$; it is generally undetermined how the population growth rate $n$ affects the relation between $k^{*}$ and $k^{* *}$.

\subsection{Existence of the Steady State Equilibrium}

A steady state equilibrium is a sequence $\{k, b\}$ that is stationary along the competitive equilibrium. This subsection examines the existence, uniqueness, and efficiency of the nontrivial steady state equilibrium. The uniqueness and efficiency may depend on the inequality $k^{*} \lesseqgtr k^{* *}$. We therefore will examine each case in turn.

Case I: $k^{*}<k^{* *}$

This is the case wherein the economy has a higher $p$ and $\tau^{l}$ and a lower $\tau^{w}$. The economy experiences an aging population and carries a heavy social security burden. We will initially focus on the steady state in which the government sells bonds $(b>0)$ or in which budget constraints are balanced in each period $(b=0)$. We then consider the steady state in which the government buy bonds $(b<0)$.

\section{Proposition 1:}

(i) There may be two dynamically inefficient steady state equilibria with $(k, b) \gg 0$, if $G\left(k^{* *}\right)<0$.

(ii) There is at least one dynamically inefficient steady state equilibrium with $(k, b) \gg 0$, if $G\left(k^{* *}\right)>0$.

(iii) There is a dynamically inefficient steady state equilibrium with $(k, b)=\left(k^{* *}, 0\right)$, if 
$G\left(k^{* *}\right)=0$. In addition, there is a dynamically inefficient steady state equilibrium with $(k, b) \gg 0$, if $G^{\prime}\left(k^{* *}\right)<H^{\prime}\left(k^{* *}\right)$.

Proof: As depicted in Figures $3 \mathrm{a}-3 \mathrm{~d}, H(\cdot) \geq 0$ holds for $k \in\left(k^{*}, k^{* *}\right]$. If there is a steady state equilibrium with $b \geq 0$, the capital stock for this equilibrium is in the interval $\left(k^{*}, k^{* *}\right]$. Therefore, the steady state with $b \geq 0$, if it exists, is dynamically inefficient.

The function $H(\cdot)$ tends to be the vertical asymptote $k=k^{*}$ as $k \rightarrow k^{*}$, such that $\lim _{k \rightarrow k^{*}} H(k)>$ $\lim _{k \rightarrow k^{*}} G(k)$ holds if $k$ approaches $k^{*}$ from the right. At $k=k^{* *}, H\left(k^{* *}\right)=0$ holds. If $G\left(k^{* *}\right)<0$ holds, then there may be two steady state equilibria with $(k, b) \gg 0$, as depicted in Figure 3 a. If $G\left(k^{* *}\right)>0$ holds, then there exists at least one steady state equilibrium with $(k, b) \gg 0$, according to the Intermediate Value Theorem (see Fig. 3b). If $G\left(k^{* *}\right)=0$ holds, $G(\cdot)$ and $H(\cdot)$ cross at $(k, b)=\left(k^{* *}, 0\right)$ (see Figs. 3c and 3d). In addition, if $G^{\prime}\left(k^{* *}\right)<H^{\prime}\left(k^{* *}\right)$, then $G(\cdot)$ and $H(\cdot)$ intersect in the interval $\left(k^{*}, k^{* *}\right)$ (see Fig. 3c). Q.E.D.

The result in Proposition 1 indicates that the inequality $G\left(k^{* *}\right) \lesseqgtr 0$ plays an important role in determining the number of the steady state equilibria with $b \geq 0$. If $G\left(k^{* *}\right)<0$, the economy may obtain two steady state equilibria with $(k, b) \gg 0$ (see Fig. 3a). One equilibrium is characterized by a lower $k$ and a higher $b$, and the other is characterized by a higher $k$ and a lower $b$. On the other hand, if $G\left(k^{* *}\right)>0$, there may be a unique steady state equilibrium with $(k, b) \gg 0$ (see Fig. 3b). If $G\left(k^{* *}\right)=0$, there is a steady state equilibrium with a zero level of public debt, $b=0$ (see Figs. 3c and 3d). Moreover, there is also a steady state equilibrium with $(k, b) \gg 0$ if $G^{\prime}\left(k^{* *}\right)<H^{\prime}\left(k^{* *}\right)$ (see Fig. 3c), although there may be no steady state equilibrium with $(k, b) \gg 0$ if $G^{\prime}\left(k^{* *}\right)>H^{\prime}\left(k^{* *}\right)$ (see Fig. 3d).

The steady state equilibrium with a nonnegative stock of public debt, $b \geq 0$, implies that the government runs a deficit or balances its budget. At the steady state with $b>0$, the amount of social security payments is greater than that of the social security tax revenue: $p \tau^{l} /(1+n)>$ 
$\tau^{w} w(k)$. The tax revenue shortage is solved by issuing public debt. On the other hand, at the steady state with $b=0$, the revenue and the payments are balanced in each period.

The steady state with $b \geq 0$ is dynamically inefficient. This inefficiency arises from the fact that $k^{*}<k^{* *}$, which indicates a low $\tau^{w}$ and high $p$ and $\tau^{l}$. The interpretation of these three factors is as follows. First, a lower rate of social security tax induces agents to save more. This positive income effect leads to overaccumulation of capital. Second, the expectation of greater longevity induces agents to save more in preparation for their consumption in old age, which also leads to an overaccumulation of capital. Finally, a higher amount of social security benefit implies the impossibility that the government cannot fully finance the social security payment by social security tax. The government funds a part of this payment by issuing public debt so that $(1+n) b>R(k) b$ holds, i.e., $n+\delta>f^{\prime}(k)$. Therefore, the overaccumulation of capital appears to be in equilibrium.

Although Proposition 1 focuses on the steady state equilibrium with $b \geq 0$, there could be an equilibrium with a negative stock of public debt, $b<0$ : in this case, the government buys bonds rather than sells them. In particular, there may be two equilibria with $b<0$ : the one is characterized by $k<k^{*}$ (see Figs. 3a - 3d) and the other is characterized by $k>k^{* *}$ (see Figs. 3b and 3d). The former equilibrium implies dynamic efficiency and an excess tax revenue, while the latter equilibrium implies dynamic inefficiency and a tax revenue shortage. Therefore, if there is a steady state with $k<k^{*}$ and $b<0$, the aim of achieving this equilibrium is desirable from the viewpoint of efficiency. The government should buy bonds rather than sell them. On the other hand, if there is no steady state with $k<k^{*}$ and $b<0$, but rather a steady state with $k>k^{* *}$ and $b<0$, the government should not buy bonds. The equilibrium with $k>k^{* *}$ and $b<0$ is Pareto inferior to any equilibrium with $b \geq 0$. In this case, the government should sell bonds.

Case II: $k^{*}>k^{* *}$ 
This is the case where the economy has a lower $p$ and $\tau^{l}$ and a higher $\tau^{w}$. In this case, the economy experiences lower longevity and a light social security burden. We will initially focus on a steady state with $b \geq 0$, and then consider a steady state with $b<0$.

\section{Proposition 2:}

(i) There may be two dynamically efficient steady state equilibria with $(k, b) \gg 0$, if $G\left(k^{* *}\right)<0$.

(ii) There is at least one dynamically efficient steady state equilibrium with $(k, b) \gg 0$, if $G\left(k^{* *}\right)>0$

(iii) There is a dynamically efficient steady state equilibrium with $(k, b)=\left(k^{* *}, 0\right)$, if $G\left(k^{* *}\right)=0$. In addition, there is a dynamically efficient steady state equilibrium with $(k, b) \gg 0$, if $G^{\prime}\left(k^{* *}\right)>H^{\prime}\left(k^{* *}\right)$

Proof. As depicted in Figures $4 \mathrm{a}-4 \mathrm{~d}, H(\cdot) \geq 0$ holds for $k \in\left[k^{* *}, k^{*}\right)$. If there is a steady state equilibrium with $b \geq 0$, the capital stock for this equilibrium is in the interval $\left[k^{* *}, k^{*}\right)$. Therefore, the steady state with $b \geq 0$, if it exists, is dynamically efficient. By employing the same argument as in the proof of Proposition 1, the existence of the steady state can be shown.

\section{Q.E.D.}

Shown in Figure 4 are the four types of steady states in Case II. The results of Case I and Case II differ as regards the following two points. First, in Case II, the steady state equilibrium with $b \geq 0$ is dynamically efficient, although it is dynamically inefficient in Case I. Second, in Case II, the amount of tax revenue is greater than that of the social security payments in any steady state with $b \geq 0$, whereas in Case I, the revenue is less than the total payments in any steady state with $b \geq 0$.

In Case II, there is the possibility of a steady state equilibria with $b<0$. In particular, there may be two equilibria with $b<0$, namely, one with $k<k^{* *}$ and another with $k>k^{*}$ (see Figs. 
$4 a-4 d)$. The former equilibrium implies dynamic efficiency and a tax revenue shortage, while the latter implies dynamic inefficiency and an excessive tax revenue. If the former equilibrium does not exist, then the remaining equilibrium with $b<0$ is dynamically inefficient. In such a situation, the aim of achieving a steady state with $b<0$ is not desirable, from the perspective of dynamic efficiency. Since any equilibrium with $b>0$ is dynamically efficient, the government should sell bonds in the capital market.

Case III: $k^{*}=k^{* *}$

There is no steady state equilibrium with $b \geq 0$, since $H<0 \forall k>0$, whereas steady states may exist with $b<0$. If the steady state is characterized by $k<(>) k^{*}=k^{* *}$, then the economy is dynamically efficient (inefficient).

The results in this subsection can be summarized as follows: in Case I $\left(k^{*}<k^{* *}\right)$, where longevity is high and the social security burden is heavy, the steady state equilibrium with $b \geq 0$ indicates dynamic inefficiency, and implies a tax revenue shortage (if $b>0$ ) or a balanced budget (if $b=0$ ). In Case II $\left(k^{*}>k^{* *}\right)$, where longevity is low and the social security burden is light, the steady state equilibrium with $b \geq 0$ indicates dynamic efficiency and an excess tax revenue (if $b>0$ ) or balanced budget (if $b=0$ ). Thus, there is a loss of efficiency when the government sells bonds in Case I, but there is no such loss in Case II. Moreover, in both cases, there may be either a dynamically efficient or an inefficient steady state equilibrium with $b<0$. If there is a dynamically efficient equilibrium with $b<0$, the government should buy bonds in the capital market, in order to achieve efficiency.

As argued in the Introduction, Japan now faces problems associated with an aging population and a heavy social security payment burden. Moreover, the social security program and the government budget deficit are closely related to each other in Japan. The analysis outlined in this paper demonstrates that, in such situations, the economy may attain dynamically inefficient 
steady state with $b \geq 0$, as shown in Figure 3. Therefore, the next section undertakes a comparative static analysis focusing on the dynamically inefficient steady state equilibria with $b \geq 0$, and examines the effects of policy reform and population aging in such equilibria. As regards the preparation of the analysis in the next section, the following subsection examines the stability of the steady states with $b \geq 0$ in Case I.

\subsection{Stability of the Steady State Equilibrium}

This subsection aims to examine the stability of the dynamically inefficient equilibria with $b \geq 0$ in Case I. That is, it considers whether the competitive equilibrium converges to a steady state, and to which of the steady states the economy converges if there are multiple steady state equilibria. It is assumed that the number of steady state equilibria with $(k, b) \gg 0$ is two (one) if $G\left(k^{* *}\right)<(>) 0$.

Proposition 3: Consider Case I: $k^{*}<k^{* *}$.

(i) Suppose that $G\left(k^{* *}\right)>0$ holds and that there is at most one steady state equilibrium with $(k, b) \gg 0$. The steady state equilibrium is then a saddle.

(ii) Suppose that $G\left(k^{* *}\right)<0$ holds and that there are two steady state equilibria with $k>0$ and $b \geq 0, e^{1}$ and $e^{2}$, where $e^{1}\left(e^{2}\right)$ has a lower (higher) $k$ and a higher (lower) $b$. Then, $e^{1}$ is a saddle and $e^{2}$ is a sink.

Proof: See Appendix A.

Proposition 3 shows the stability of each steady state equilibrium with $b \geq 0$ in Case I. If $G\left(k^{* *}\right)>0$ holds, the equilibrium is a saddle. If $G\left(k^{* *}\right)<0$ holds, the steady state equilibrium with a low $k$ ( $e^{1}$ equilibrium) represents a saddle equilibrium and the equilibrium with a high $k\left(e^{2}\right.$ equilibrium) is considered as a sink. There is the possibility that two economies with very similar initial capital stocks will converge to very different steady state equilibria. The $e^{1}$ equilibrium is 
relatively efficient to the $e^{2}$ equilibrium, but the economy would converge to the $e^{2}$ equilibrium under most initial conditions, since $e^{1}$ is a saddle, whereas $e^{2}$ is a sink. Therefore, the initial values of capital and public debt play crucial roles in determining the long-run consequences for the economy.

\section{Comparative Statics}

This section focuses on the dynamically inefficient steady state equilibrium with $b \geq 0$ described in Case I. The reason for this focus is as follows. In Case I, the steady state equilibrium with $b \geq 0$ is dynamically inefficient, and thus there is a need for reducing inefficiency by implementing some kind of policy reform. Moreover, as argued in the Introduction, Japan is now faced with an aging population and a heavy social security payment burden. Such a situation is characterized by the equilibrium with $b \geq 0$, depicted in Case I. This section examines the effects of changes in economic policy or economic environment, and presents policy implications for Japan as well as for countries that are running budget deficits against a background of heavy social security payment burdens caused by an aging population.

\subsection{Effects of Policy Reform}

This subsection considers the effects of changes in $\tau^{l}, \tau^{w}$, and $\gamma$ on capital accumulation.

\section{Proposition 4:}

(i) $\partial k / \partial \tau^{l}>(<) 0$ holds at an equilibrium of $e^{1}\left(e^{2}\right)$.

(ii) $\partial k / \partial \tau^{w}<(>) 0$ holds at an equilibrium of $e^{1}\left(e^{2}\right)$.

(iii) When $\tau^{l}=0, \partial k / \partial \gamma>(<) 0$ holds at an equilibrium of $e^{1}\left(e^{2}\right)$. When $\tau^{l}>0$, a higher $\gamma$ leads to either a higher or lower level of capital. 


\section{Proof: See Appendix B.}

An increase in $\tau^{l}$ affects capital in the following two ways. A higher $\tau^{l}$ leads to less savings, thereby diminishing capital accumulation. Moreover, a higher $\tau^{l}$ requires a higher level of public debt in order to finance social security payments, which reduces capital. These factors imply a negative effect of $\tau^{l}$. On the other hand, a lower level of capital caused by a higher $\tau^{l}$ yields a higher rate of interest that implies lower social security benefits are evaluated for the youth $\left(\tau^{l} / R\right)$. Young agents are likely to increase their savings in response to the lower discounted present value of the benefits. This positive direction of $\tau^{l}$ as regard savings enhances the accumulation of capital. At $e^{1}\left(e^{2}\right)$ equilibrium, the negative effect is less (greater) than the positive effect. This result differs from that proposed by Gertler (1997), who demonstrated that social security benefits unambiguously reduce capital. The result in opposition to that of Gertler (1997) occurs at an equilibrium of $e^{1}$.

An increase in $\tau^{w}$ affects capital in the following two ways. First, a higher $\tau^{w}$ has a negative income effect, which decreases capital. This represents a negative effect of $\tau^{w}$ on capital. Second, a higher $\tau^{w}$ leads to a larger amount of revenue from social security tax. This condition decreases the stock of public debt, which weakens the crowding-out effect of public debt on capital. This is a positive effect of $\tau^{w}$ on capital. At $e^{1}\left(e^{2}\right)$ equilibrium, the negative effect is greater (less) than the positive effect. This result differs from that of Pecchenino and Pollard (1997), who demonstrated that social security tax reduces capital. The opposite result was obtained by the present analysis at an equilibrium of $e^{2} .^{10}$

An increase in $\gamma$ (i.e., a higher annuitization rate) affects capital in the following two ways. First, a higher $\gamma$ leads to a lower level of bequests, thereby decreasing savings and capital. This

10 Pecchenino and Pollard (1997) assumed a production function with external effects of capital and then analyzed the effects of policy reform on growth rate. However, if we adopt the neoclassical production function in their analysis, we can replace "growth rate" with "a level of capital" in their comparative statics analysis. 
negative income effect on capital yields a smaller amount of revenue from social security tax, which requires a higher level of public debt to finance social security payments and thus crowds out capital. These results imply a negative effect of $\gamma$ on capital. Second, a higher $\gamma$ leads to a lower discounted present value of social security benefits $\left(\tau^{l} / R\right)$. This implies a positive income effect on savings and capital. Moreover, a higher $\gamma$ requires a lower stock of public debt in a capital market, which diminishes the crowding-out effect of debt on capital. These results imply a positive effect of $\gamma$ on capital. When $\tau^{l}>0$, the effect of $\gamma$ is ambiguous. However, when $\tau^{l}=0$, the positive effect is greater (less) than the negative effect at an equilibrium of $e^{1}\left(e^{2}\right)$.

The results in Proposition 4 indicate that the consequences of policy reform depend on whether the economy is at an equilibrium of $e^{1}$ or $e^{2}$. When the economy experiences an equilibrium of $e^{1}\left(e^{2}\right)$, the policy maker should decrease (increase) social security benefits per capita, increase (decrease) social security tax, and decrease (increase) the annuitization rate in order to improve the dynamic inefficiency of the equilibrium.

The combination of an increase in $\gamma$ and a decrease in $\tau^{l}$ implies a shift from a pay-as-you-go scheme to an actuarially fair pension scheme. When the economy does not implement a payas-you-go pension scheme $\left(\tau^{l}=0\right)$, raising the annuitization rate is harmful (beneficial) to the economy at an equilibrium of $e^{1}\left(e^{2}\right)$. However, when the economy maintains the combination of the two pension schemes $\left(\tau^{l}>0\right.$ and $\left.\gamma>0\right)$, then the effect of annuitization is ambiguous. We can only conclude that a decrease in social security benefits $\left(\tau^{l}\right)$ is beneficial (harmful) to the economy at an equilibrium of $e^{1}\left(e^{2}\right)$. The social security reform aiming at an actuarially fair annuity is not necessarily beneficial from the viewpoint of dynamic efficiency. 


\subsection{Effects of Population Aging}

This subsection considers effects of population growth $(n)$ and longevity $(p)$ on capital accumulation.

\section{Proposition 5:}

(i) A higher $n$ leads to either a higher or lower level of capital.

(ii) When $\gamma=1$ and $\tau^{w}(1+p)(2+p) / p \geq 1, \partial k / \partial p>(<) 0$ holds at an equilibrium of $e^{1}\left(e^{2}\right)$. When $\gamma<1$, a higher $p$ leads to either a higher or lower level of capital.

Proof: See Appendix B.

A higher $n$ leads to a lower $k$, given the other variables. This result implies a negative effect on capital. On the other hand, a higher $n$ yields a lighter aggregate social security benefit burden and thus a lower level of public debt. This lessens the crowding-out effect of public debt on capital. We see in this scenario the two opposite effects of population growth rate on capital. Therefore, the effect of aging caused by a lower rate of population growth remains generally ambiguous.

A higher $p$ affects capital in the following two ways. First, a higher expectancy of longevity induces agents to save more, which enhances capital accumulation. This represents a positive effect on capital. Second, a higher $p$ reduces unintentional bequests. This negative income effect on savings decreases capital. Moreover, a higher $p$ implies a larger amount of aggregate social security benefits. This scenario requires a larger amount of public debt, thereby reducing the accumulation of capital. These results imply a negative effect on capital. If $\gamma=1$ and $\tau^{w}(1+p)(2+p) / p \geq 1$, then the positive effect is greater (less) than the negative effect at an

equilibrium of $e^{1}\left(e^{2}\right)$. The consequence of annuitization at an equilibrium of $e^{2}$ is in opposition to that described in Pecchenino and Pollard (1997). 


\section{An Alternative Form of Social Security Payments}

Section 4 demonstrated that the economy experiences excessive saving (i.e., a dynamically inefficient steady state) when a social security program is financed by the issuance of public debt (Proposition 1). This result is in opposition to many previous findings that social security reduces saving (see, for example, Pecchenino and Pollard (1997)). Readers may suspect that this discrepancy between results may arise from the assumption of lump-sum benefits. This section assumes an alternative form of social security, in which payments are calculated as a replacement rate on the next generation's wages. Under this alternative form, it is shown that the economy reflects excessive saving. Therefore, it could be argued that excessive saving is a probable consequence when a social security program is financed by public debt.

Suppose that the payments for the older individuals in generation $t$ are calculated by a replacement rate on the next generation's wages: $\tau_{t+1}^{l}=\zeta w_{t+1}$, where $\zeta>0$ is a constant parameter. $^{11}$ An agent who pays a social security tax, $\tau^{w} w_{t}$, in youth will receive the social security payment, $\zeta w_{t+1}$, upon reaching old age. Then, by replacing $\tau^{l}$ with $\zeta w_{t}$, the government budget constraint is rewritten as $B_{t+1}+N_{t} \tau^{w} w_{t}=R_{t} B_{t}+p N_{t-1} \zeta w_{t}$. Dividing both sides by $N_{t}$ and rearranging the equation, the budget equation in equilibrium is

$$
(1+n) b_{t+1}=R\left(k_{t}\right) b_{t}+\left(\frac{p \zeta}{1+n}-\tau^{w}\right) w\left(k_{t}\right)
$$

The inequality $p \zeta /(1+n)>\tau^{w}$ implies that social security payments are greater than the total tax revenue. ${ }^{12}$

\footnotetext{
11 The qualitative results regarding the efficiency and the number of steady state equilibria do not change if we assume that payments are calculated by a replacement rate of the next generation's wage income tax, $\zeta \tau^{w} w_{t+1}$.

12 The inequality $p \zeta /(1+n)>\tau^{w}$ implies that the economy has higher expected longevity, a higher rate of replacement, a lower rate of population growth, and a lower rate of social security tax.
} 
The capital market clearing condition (12) is rewritten as

$$
\begin{aligned}
& (1+n) k_{t+1}+\frac{\zeta w\left(k_{t+1}\right)}{(1+p) R\left(k_{t+1}\right)\left(1+\frac{\gamma}{p}(1-p)\right)} \\
= & \frac{p}{1+p}\left\{\left(1-\tau^{w}\right) w\left(k_{t}\right)+(1-\gamma)(1-p) R\left(k_{t}\right)\left(k_{t}+b_{t}\right)\right\}-R\left(k_{t}\right) b_{t}-\left(\frac{p \zeta}{1+n}-\tau^{w}\right) w\left(k_{t}\right)
\end{aligned}
$$

by replacing $\tau^{l}$ with $\zeta w_{t+1}$. Thus, (14) and (15) constitute a planar system of $(k, b)$ when the social security payment is calculated as a replacement rate on wages.

We proceed with the equilibrium analysis by using a phase diagram. The phase diagram for (15) is

$$
\begin{aligned}
& k_{t+1} \geqslant k_{t} \Leftrightarrow b_{t} \leqslant \tilde{G}\left(k_{t}\right) \equiv \frac{\frac{p}{1+p}\left\{\left(1-\tau^{w}\right) w\left(k_{t}\right)+(1-\gamma)(1-p) R\left(k_{t}\right) k_{t}\right\}}{\left\{1-\frac{p}{1+p}(1-\gamma)(1-p)\right\} R\left(k_{t}\right)} \\
& +\frac{-\left(\frac{p \zeta}{1+n}-\tau^{w}\right) w\left(k_{t}\right)-(1+n) k_{t}-\frac{\zeta w\left(k_{t}\right)}{(1+p) R\left(k_{t}\right)\left(1+\frac{\gamma(1-p)}{p}\right)}}{\left\{1-\frac{p}{1+p}(1-\gamma)(1-p)\right\} R\left(k_{t}\right)},
\end{aligned}
$$

and the phase diagram for (14) is

$$
b_{t+1} \geqslant b_{t} \Leftrightarrow b_{t} \gtrless \tilde{H}\left(k_{t}\right) \equiv \frac{\left(\frac{p \zeta}{1+n}-\tau^{w}\right) w\left(k_{t}\right)}{1+n-R\left(k_{t}\right)} \quad \text { if } k_{t} \lessgtr k^{*} .
$$

(16) implies that the value of $b$ depends on the two following inequalities: $p \zeta /(1+n) \gtrless \tau^{w}$ and $k_{t} \lessgtr k^{*}{ }^{13}$ Focusing on the inequality $p \zeta /(1+n) \gtrless \tau^{w}$, the types of equilibria are classified into the following three categories.

(i) $p \zeta /(1+n)>\tau^{w}$ (Fig. 5a). This is the case involving excessive social security payment burden. As depicted in Fig. 5a, there may be two dynamically inefficient steady state equilibria with $(k, b) \gg 0$, and one dynamically efficient equilibrium with $k>0$ and $b<0$. This result corresponds the results of Proposition 1 (i), which characterizes dynamically inefficient multiple steady state equilibria with $(k, b) \gg 0$, where payments are greater than the tax revenue.

\footnotetext{
13 When the payments are calculated at a constant level, there is a critical value $k^{* *}$ (see Eq. (13)). On the other hand, when the payments are calculated as a replacement rate on wages, this critical value disappears.
} 
(ii) $p \zeta /(1+n)>\tau^{w}$ (Fig. 5b). In this case, the tax revenue is sufficient to cover social security payments. There may be one dynamically efficient steady state equilibrium with $(k, b) \gg 0$ and one dynamically inefficient steady state equilibrium with $k>0$ and $b<0$. This result corresponds to that demonstrated in Proposition 2 (ii).

(iii) $p \zeta /(1+n)=\tau^{w}$. In this case, the tax revenue is equal to the amount of the social security payments. Although the government can borrow (lend) resources from (to) individuals through the capital market, there is no public debt issue in the possible steady states. The capital market clearing condition is reduced to the following equation:

$$
\begin{aligned}
& (1+n) k_{t+1}+\frac{\zeta w\left(k_{t+1}\right)}{(1+p) R\left(k_{t+1}\right)\left(1+\frac{\gamma}{p}(1-p)\right)} \\
= & \frac{p}{1+p}\left\{\left(1-\tau^{w}\right) w\left(k_{t}\right)+(1-\gamma)(1-p) R\left(k_{t}\right) k_{t}\right\}-\left(\frac{p \zeta}{1+n}-\tau^{w}\right) w\left(k_{t}\right) .
\end{aligned}
$$

The steady state equilibrium, if it exists, is not necessarily unique (see Galor and Ryder (1989)). Moreover, its efficiency depends on the parameter values. In order to investigate the dynamic efficiency of the steady state equilibrium in case (iii), let us specify the production function as $f(k)=k^{\alpha}, \alpha \in(0,1)$. Then, the golden rule level of capital and the competitive equilibrium level of capital are, respectively,

$$
k^{*}=\left(\frac{\alpha}{\delta+n}\right)^{\frac{1}{1-\alpha}} \text { and } k=\left(\frac{\frac{p}{1+p}\left\{\left(1-\tau^{w}\right)(1-\alpha)+(1-\gamma)(1-p) \alpha\right\}}{(1+n)+\frac{\zeta(1-\alpha)}{(1+p) \alpha\left(1+\frac{\gamma(1-p)}{p}\right)}}\right)^{\frac{1}{1-\alpha}}
$$

It is easily shown that $k^{*}>k$ holds if $n=\delta=0$, and that $k^{*}<k$ holds if $\left(\alpha, p, \zeta, \tau^{w}, \delta, \gamma, n\right)=$ $(1 / 4,9 / 10,1 / 10,1 / 10,1,0,0)$

The result in this section implies that excessive saving (i.e., a dynamically inefficient equilibrium) could appear to be an equilibrium regardless of the form of social security payment. Excessive saving is a probable consequence when a social security program is financed by public debt. 


\section{Concluding Remarks}

This study examined social security payments financed by public debt in an overlapping generations model of growth and aging. It was found that (i) dynamically inefficient, multiple equilibria may exist when a social security program is financed by issuing public debt; and (ii) effects of pension reform and population aging depend heavily on the state of the equilibrium.

The results of this paper have policy implications for an economy with aging and deficits in the following two areas. First, when there is a tax revenue shortage, financing social security payments by issuing public debt may yield a dynamically inefficient equilibrium (see the results in Proposition 1 and case (i) in Section 6). With this scenario, there could also be a dynamically efficient equilibrium with a negative stock of public debt. Hence, the government should aim to achieve this efficient equilibrium by buying bonds to attain efficiency. Second, when the economy eventually falls into a dynamically inefficient equilibrium, in which the government sells bonds, there will be a need for policy reform. However, if there are two steady state equilibria (Proposition 1(ii) and (iii)), the effects of policy reform are entirely different between the two cases (see Proposition 4). For example, reforming social security from a pay-as-you-go scheme to an actuarially fair pension scheme in preparation for population aging would be desirable for the one equilibrium but would be undesirable for the other equilibrium. Policy-makers therefore need to exercise caution when implementing social security policy reform.

In closing, a further direction for the present analysis should be noted. One natural direction for such studies would be to extend the present model by including the extended family system and endogenous fertility as factors. This extension has been suggested by Cigno and Rosati (1996, 1997), who examined several models that captured the effects of social security on household saving behaviors; they demonstrated that a model including both the extended family system 
and endogenous fertility provided a good fit with the empirical results. Thus, extending the present model to one reflecting their suggestions would lead to further fruitful results as regards the analysis of social security and household saving. 


\section{Appendix A: Proof of Proposition 3}

We first derive the Jacobian matrix at any steady state $(k, b)$ of a planar system under the assumption $k^{* *}<k^{*}$, which consists of (11) and (12).

$$
J=\left[\begin{array}{ll}
\eta_{1} & \eta_{2} \\
\eta_{3} & \eta_{4}
\end{array}\right]
$$

where

$$
\begin{aligned}
\eta_{1} & \equiv \frac{\frac{p}{1+p}\left[\left(1-\tau^{w}\right) w^{\prime}(k)+(1-\gamma)(1-p)\left\{R^{\prime}(k)(k+b)+R(k)\right\}\right]-\left\{R^{\prime}(k) b-\tau^{w} w^{\prime}(k)\right\}}{\xi\left(k ; n, p, \gamma, \tau^{l}\right)}>0 \\
\eta_{2} & \equiv \frac{\left(\frac{p}{1+p}(1-\gamma)(1-p)-1\right) R(k)}{\xi\left(k ; n, p, \gamma, \tau^{l}\right)}<0 \\
\eta_{3} & \equiv \frac{R^{\prime}(k) b-\tau^{w} w^{\prime}(k)}{1+n}<0 \\
\eta_{4} & \equiv \frac{R(k)}{1+n} \in(0,1)
\end{aligned}
$$

and

$$
\xi\left(k ; n, p, \gamma, \tau^{l}\right) \equiv(1+n)-\frac{\tau^{l} R^{\prime}(k)}{(1+p)\left(1+\frac{\gamma}{p}(1-p)\right)(R(k))^{2}}>0 .
$$

Note that $\eta_{4} \in(0,1)$ holds, since $R(k)<1+n$ at a steady state with $k \in\left(k^{*}, k^{* *}\right)$.

The slopes of $G(\cdot)$ and $H(\cdot)$ at the steady state are

$$
G^{\prime}(k)=\frac{1-\eta_{1}}{\eta_{2}}, H^{\prime}(k)=\frac{\eta_{3}}{1-\eta_{4}}
$$

For any $(k, b) \gg 0$, its trace and determinant are

$$
\operatorname{trJ}=\eta_{1}+\eta_{4}>0
$$

$\operatorname{det} J=\eta_{1} \eta_{4}-\eta_{2} \eta_{3}$

$$
=\frac{p R(k)}{(1+p) \xi\left(k ; n, p, \gamma, \tau^{l}\right)(1+n)}\left[w^{\prime}(k)\left\{\left(1-\tau^{w}\right)+(1-\gamma)(1-p)\right\}+(1-\gamma)(1-p)\left\{R^{\prime}(k) k+R(k)\right\}\right]
$$

$>0 ; R^{\prime}(k) k+R(k)>0$ holds by Assumption 1 (ii). 
Moreover, it holds that

$$
\Delta=(\operatorname{tr} J)^{2}-4 \operatorname{det} J=\left(\eta_{1}+\eta_{4}\right)^{2}-4\left(\eta_{1} \eta_{4}-\eta_{2} \eta_{3}\right)=\left(\eta_{1}-\eta_{4}\right)^{2}+4 \eta_{2} \eta_{3}>0
$$

which implies that $J$ has two positive eigenvalues at each steady state.

The eigenvalues of $J$ are obtained by solving the following equation:

$$
p(\lambda)=\left|\begin{array}{cc}
\eta_{1}-\lambda & \eta_{2} \\
\eta_{3} & \eta_{4}-\lambda
\end{array}\right|=\lambda^{2}-\operatorname{tr} J \lambda+\operatorname{det} J=0
$$

We immediately obtain

$$
p(-1)=1+\operatorname{tr} J+\operatorname{det} J>0
$$

since $\operatorname{tr} J>0$ and $\operatorname{det} J>0$ hold. Hence, the only remaining task is to confirm the sign of $p(1)$.

At an $e^{1}$ equilibrium, it holds that $G^{\prime}(k)>H^{\prime}(k)$ (see Fig. 3a). With (17) and $1-\eta_{4}>0$, this inequality is rewritten as:

$$
1-\left(\eta_{1}+\eta_{4}\right)+\left(\eta_{1} \eta_{4}-\eta_{2} \eta_{3}\right)<0 \text {, i.e., } p(1)<0 \text {. }
$$

Thus, $p(-1)>0$ and $p(1)<0$ imply that $e^{1}$ equilibrium is a saddle type of equilibrium.

At an $e^{2}$ equilibrium, it holds that $G^{\prime}(k)<H^{\prime}(k)$; in other words,

$$
1-\left(\eta_{1}+\eta_{4}\right)+\left(\eta_{1} \eta_{4}-\eta_{2} \eta_{3}\right)>0 \text {, i.e., } p(1)>0 \text {. }
$$

Since $H^{\prime}(k)<0$ holds at an $e^{2}$ equilibrium, it also holds that $G^{\prime}(k)=\left(1-\eta_{1}\right) / \eta_{2}<0$, which implies that $\eta_{1} \in(0,1)$. Furthermore, it holds that $\eta_{4}=R(k) /(1+n) \in(0,1)$. These results lead to the conclusion that $\operatorname{tr} J=\eta_{1}+\eta_{4} \in(0,2)$. Therefore, both eigenvalues are within the range $(-1,1)$ and the equilibrium is a sink. Q.E.D.

\section{Appendix B: Proof of Propositions 4 and 5}


Total differentiation of (12) and (13) leads to

$$
\begin{aligned}
& {\left[\begin{array}{cc}
1-\eta_{1} & -\eta_{2} \\
-\eta_{3} & 1-\eta_{4}
\end{array}\right]\left[\begin{array}{c}
d k \\
d b
\end{array}\right]} \\
& =\left[\begin{array}{c}
\frac{-\frac{1}{(1+p) R(k)(1+\gamma(1-p) / p)}-\frac{p}{1+n}}{\xi\left(k ; n, p, \gamma, \tau^{l}\right)} \\
\frac{p}{(1+n)^{2}}
\end{array}\right] d \tau^{l}+\left[\begin{array}{c}
\frac{1}{1+p} w(k) \\
\xi\left(k ; n, p, \gamma, \tau^{l}\right) \\
\frac{-w(k)}{1+n}
\end{array}\right] d \tau^{w}+\left[\begin{array}{c}
\frac{\frac{1-p}{1+p}\left\{\frac{\tau^{l}}{p R(k)(1+\gamma(1-p) / p)^{2}}-p R(k)(k+b)\right\}}{\xi\left(k ; n, p, \gamma, \tau^{l}\right)} \\
0
\end{array}\right] d \gamma \\
& +\left[\begin{array}{c}
\frac{-k+\frac{p \tau^{l}}{(1+n)^{2}}}{\xi\left(k ; n, p, \gamma, \tau^{l}\right)} \\
-\left[b+\frac{p \tau^{l}}{(1+n)^{2}}\right]\left(\frac{1}{1+n}\right)
\end{array}\right] d n+\left[\begin{array}{c}
\phi\left(k ; n, p, \gamma, \tau^{l}\right) \\
\frac{\tau^{l}}{(1+n)^{2}}
\end{array}\right] d p
\end{aligned}
$$

where

$$
\begin{aligned}
\phi\left(k ; n, p, \gamma, \tau^{l}\right) \equiv & \frac{\frac{\tau^{l}}{(1+p)^{2} R(k)(1+\gamma(1-p) / p)^{2}}\left\{1-\gamma\left(1+1 / p^{2}\right)\right\}}{\xi\left(k ; n, p, \gamma, \tau^{l}\right)} \\
& +\frac{\left(\frac{1}{1+p}\right)^{2}\left\{\left(1-\tau^{w}\right) w(k)+(1-\gamma)\left(1-2 p-p^{2}\right) R(k)(k+b)\right\}-\frac{\tau^{l}}{1+n}}{\xi\left(k ; n, p, \gamma, \tau^{l}\right)} .
\end{aligned}
$$

The sign of $\phi\left(k ; n, p, \gamma, \tau^{l}\right)$ remains ambiguous.

Since our focus is on the dynamically inefficient equilibrium, (18) and (19) hold. The determinant of the matrix on the left-hand side, $|D|$, is:

$$
\begin{aligned}
|D| & =1-\left(\eta_{1}+\eta_{4}\right)+\left(\eta_{1} \eta_{4}-\eta_{2} \eta_{3}\right) \\
& =p(1)\left\{\begin{array}{l}
<0 \\
<\text { at } e^{1} \text { equilibrium; from (18); } \\
>0 \text { at } e^{2} \text { equilibrium; from (19). }
\end{array}\right.
\end{aligned}
$$

Also, $1-\eta_{4}=1-R(k) /(1+n)>0$ holds in the dynamically inefficient steady state equilibrium.

The effect of $\tau^{l}$ :

$$
\begin{aligned}
\frac{\partial k}{\partial \tau^{l}} & =\frac{1}{|D|}\left|\begin{array}{cc}
\frac{-\frac{1}{(1+p) R(k)(1+\gamma(1-p) / p)}-\frac{p}{1+n}}{\xi\left(k ; n, p, \gamma, \tau^{l}\right)} & -\eta_{2} \\
\frac{p}{(1+n)^{2}} & 1-\eta_{4}
\end{array}\right| \\
& =\frac{1}{|D|}\left[\left\{\frac{-\frac{1}{(1+p) R(k)(1+\gamma(1-p) / p)}-\frac{p}{1+n}}{\xi\left(k ; n, p, \gamma, \tau^{l}\right)}\right\}\left(1-\eta_{4}\right)+\eta_{2} \frac{p}{(1+n)^{2}}\right] .
\end{aligned}
$$


The sign of the value in the square brackets is negative. Thus, we obtain

$$
\partial k / \partial \tau^{l} \gtrless 0 \text { if and only if }|D|=p(1) \lessgtr 0 .
$$

\section{The effect of $\tau^{w}$ :}

$$
\frac{\partial k}{\partial \tau^{l}}=\frac{1}{|D|}\left|\begin{array}{cc}
\frac{\frac{1}{1+p} w(k)}{\xi\left(k ; n, p, \gamma, \tau^{l}\right)} & -\eta_{2} \\
\frac{-w(k)}{1+n} & 1-\eta_{4}
\end{array}\right|=\frac{1}{|D|}\left[\frac{\frac{1}{1+p} w(k)}{\xi\left(k ; n, p, \gamma, \tau^{l}\right)}\left(1-\eta_{4}\right)-\eta_{2} \frac{w(k)}{1+n}\right]
$$

The sign of the value in the square brackets is positive. Thus, we obtain

$$
\partial k / \partial \tau^{w} \gtrless 0 \text { if and only if }|D|=p(1) \gtrless 0 \text {. }
$$

\section{The effect of $\gamma$ :}

$$
\begin{aligned}
\frac{\partial k}{\partial \gamma} & =\frac{1}{|D|}\left|\begin{array}{cc}
\frac{\frac{1-p}{1+p}\left\{\frac{\tau^{l}}{p R(k)(1+\gamma(1-p) / p)^{2}}-p R(k)(k+b)\right\}}{\xi\left(k ; n, p, \gamma, \tau^{l}\right)} & -\eta_{2} \\
0 & 1-\eta_{4}
\end{array}\right| \\
& =\frac{1}{|D|} \frac{\frac{1-p}{1+p}\left[\frac{\tau^{l}}{p R(k)(1+\gamma(1-p) / p)^{2}}-p R(k)(k+b)\right]}{\xi\left(k ; n, p, \gamma, \tau^{l}\right)}\left(1-\eta_{4}\right) .
\end{aligned}
$$

The first term in the square brackets, $\frac{\tau^{l}}{p R(k)(1+\gamma(1-p) / p)^{2}}$, is positive, whereas the second term, $-p R(k)(k+b)$, is negative. Thus, the sign of $\partial k / \partial \gamma$ remains ambiguous. However, if $\tau^{l}=0$, the first term disappears. Thus, we obtain

$$
\partial k / \partial \gamma \lessgtr 0 \text { if and only if }|D|=p(1) \gtrless 0
$$

under the assumption that $\tau^{l}=0$.

\section{The effect of $n$ :}

$\frac{\partial k}{\partial n}=\frac{1}{|D|}\left|\begin{array}{cc}\frac{-k+\frac{p \tau^{l}}{1+n}}{\xi\left(k ; n, p, \gamma, \tau^{l}\right)} & -\eta_{2} \\ -\left[b+\frac{p \tau^{l}}{(1+n)^{2}}\right]\left(\frac{1}{1+n}\right) & 1-\eta_{4}\end{array}\right|=\frac{1}{|D|}\left[\frac{-k+\frac{p \tau^{l}}{1+n}}{\xi\left(k ; n, p, \gamma, \tau^{l}\right)}\left(1-\eta_{4}\right)-\eta_{2}\left(b+\frac{p \tau^{l}}{(1+n)^{2}}\right)\right]$.

The sign of the first term in the square brackets is ambiguous, whereas the sign of the second term is positive. Thus, the sign of $\partial k / \partial n$ remains ambiguous. 
The effect of $p$ :

$$
\frac{\partial k}{\partial p}=\frac{1}{|D|}\left|\begin{array}{cc}
\phi\left(k ; n, p, \gamma, \tau^{l}\right) & -\eta_{2} \\
\frac{\tau^{l}}{(1+n)^{2}} & 1-\eta_{4}
\end{array}\right|=\frac{1}{|D|}\left[\phi\left(k ; n, p, \gamma, \tau^{l}\right)\left(1-\eta_{4}\right)+\eta_{2} \frac{\tau^{l}}{(1+n)^{2}}\right] .
$$

Suppose that $\gamma<1$. The sign of $\phi\left(k ; n, p, \gamma, \tau^{l}\right)\left(1-\eta_{4}\right)$ is ambiguous, while the sign of $\eta_{2} \tau^{l} /(1+n)^{2}$ is negative. Thus, the sign of $\partial k / \partial p$ remains ambiguous.

Next, suppose that $\gamma=1$. In order to derive the condition that will be sufficient for determining the sign of $\phi$, we will consider the sign of $\xi \cdot \phi$.

$$
\begin{aligned}
\xi \cdot \phi & =\frac{-\tau^{l}}{(1+p)^{2} R(k)}+\left(\frac{1}{1+p}\right)^{2}\left(1-\tau^{w}\right) w(k)-\frac{\tau^{l}}{1+n} \\
& <\frac{-\tau^{l}}{(1+p)^{2}(1+n)}+\left(\frac{1}{1+p}\right)^{2}\left(1-\tau^{w}\right) w(k)-\frac{\tau^{l}}{1+n} ; \text { since } R(k)<1+n \\
& =-\left[\left(\frac{1}{1+p}\right)^{2}+1\right]\left(\frac{\tau^{l}}{1+n}\right)+\left(\frac{1}{1+p}\right)^{2}\left(1-\tau^{w}\right) w(k) .
\end{aligned}
$$

At the dynamically inefficient equilibrium, the government budget constraint leads to:

$$
((1+n)-R(k)) b=\frac{p \tau^{l}}{1+n}-\tau^{w} w(k)>0, \text { i.e., } \frac{p \tau^{l}}{1+n}-\tau^{w} w(k)>0
$$

Substituting $\frac{p \tau^{l}}{1+n}$ from (22) to (21), we obtain

$$
\begin{aligned}
\xi \cdot \phi & <-\left[\left(\frac{1}{1+p}\right)^{2}+1\right]\left(\frac{\tau^{w} w(k)}{p}\right)+\left(\frac{1}{1+p}\right)^{2}\left(1-\tau^{w}\right) w(k) \\
& =\left[-\frac{\tau^{w}}{p}+\left(\frac{1}{1+p}\right)^{2}\left\{1-\frac{\tau^{w}}{p}-\tau^{w}\right\}\right] w(k) .
\end{aligned}
$$

The sign of the value in the square brackets is non-positive if $\tau^{w}(1+p)(2+p) / p \geq 1$. Since $\xi>0$, the first term in the square brackets of $(20)$ is negative if $\gamma=1$ and $\tau^{w}(1+p)(2+p) / p \geq 1$, and the second term is negative. Thus, we obtain

$$
\partial k / \partial p \gtrless 0 \text { if and only if }|D|=p(1) \lessgtr 0
$$

under the assumption $\gamma=1$ and $\tau^{w}(1+p)(2+p) / p \geq 1$. Q.E.D. 


\section{References}

Azariadis, C., 1993, Intertemporal Macroeconomics, Blackwell.

Blanchard, O., 1985, Debt, Deficits and Finite Horizons, Journal of Political Economy 93, 223-247.

Bental, B., 1989, The Old Age Security Hypothesis and Optimal Population Growth, Journal of Population Economics 1, 285-301.

Cigno, A., 1993, Intergenerational Transfers without Altruism: Family, Market and State, European Journal of Political Economy 9, 505-18.

Cigno, A., and Rosati, F.C., 1996, Jointly Determined Saving and Fertility: Theory, and Estimates for Germany, Italy, UK and USA, European Economic Review 40, 1561-1589.

Cigno, A., and Rosati, F.C., 1997, Rise and Fall of the Japanese Saving Rate: The Role of Social Security and Intra-family Transfers, Japan and the World Economy 9, 81-92.

Futagami, K. and Nakajima, T., 2001, Population Aging and Economic Growth, Journal of Macroeconomics 23, 31-44.

Galor, O. and Ryder, H., 1989, Existence, Uniqueness, and Stability of Equilibrium in an Overlapping-Generations Model with Productive Capital, Journal of Economic Theory 49, $360-75$.

Gertler, M., 1997, Government Debt and Social Security in a Life-Cycle Economy, NBER Working Paper No. 6000.

Hatta, T. and Oguchi, N., 1992, Changing the Japanese Social Security System from Pay as You Go to Actuarially Fair, Wise, D., ed., Topics in the Economics of Aging: A National Bureau of Economic Research Project Report, University of Chicago Press, 207-245.

Meijdam, L. and Verbon, H., 1997, Aging and Public Pensions in an OverlappingGenerations Model, Oxford Economic Papers 49, 29-42.

Pecchenino, P. and Pollard, R., 1997, The Effects of Annuities, Bequests, and Aging in an Overlapping Generations Model of Endogenous Growth, Economic Journal 107, 26-46.

Pecchenino, P., and Utendorf, K., 1999, Social Security, Social Welfare, and the Aging Population, Journal of Population Economics 12, 607-623.

Raut, L.K., Capital Accumulation, Income Distribution and Endogenous Fertility in an Overlapping Generations General Equilibrium Model, Journal of Development Economics $34,123-50$.

Romer, P., 1986, Increasing Returns and Long-run Growth, Journal of Political Economy 94, 1002-10037.

Weil, P., 1989, Overlapping Families of Infinitely-Lived Agents, Journal of Public Economics 38, 410-421. 
Zhang, J. and Nishimura, K., 1993, The Old-Age Security Hypothesis Revisited, Journal of Development Economics 41, 191-202.

Zhang, J., 1995, Social Security and Endogenous Growth, Journal of Public Economics 58, $185-213$.

Zhang, J. and Zhang, J., 1995, The Effects of Social Security on Population and Output Growth, Southern Economic Journal 62, 440-50. 
Figure 1

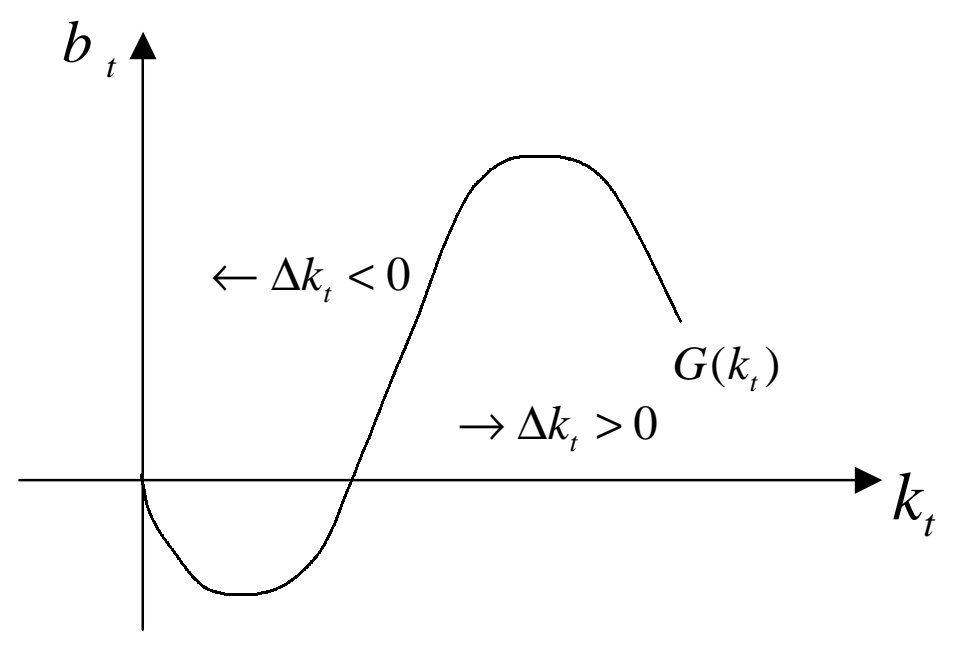

Figure 2

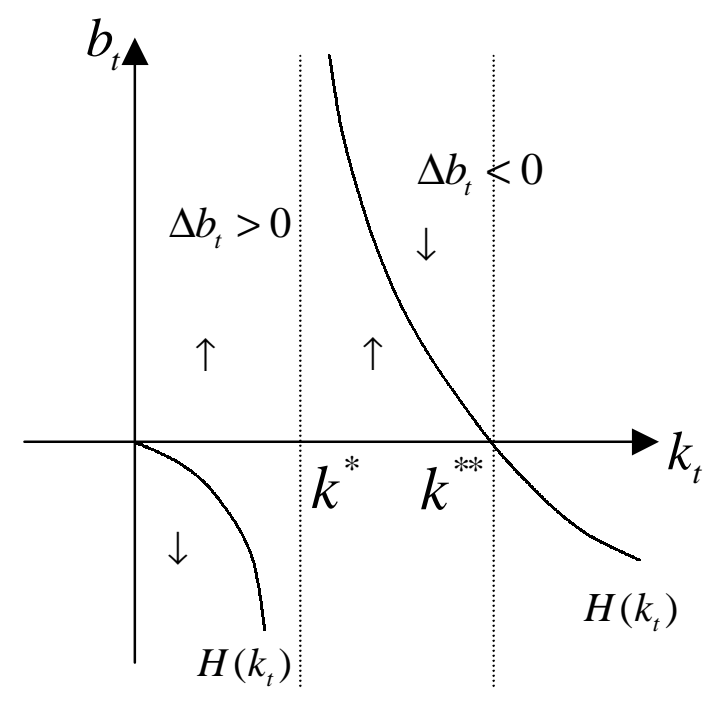

Figure $2 a: k^{*}<k^{* *}$ case

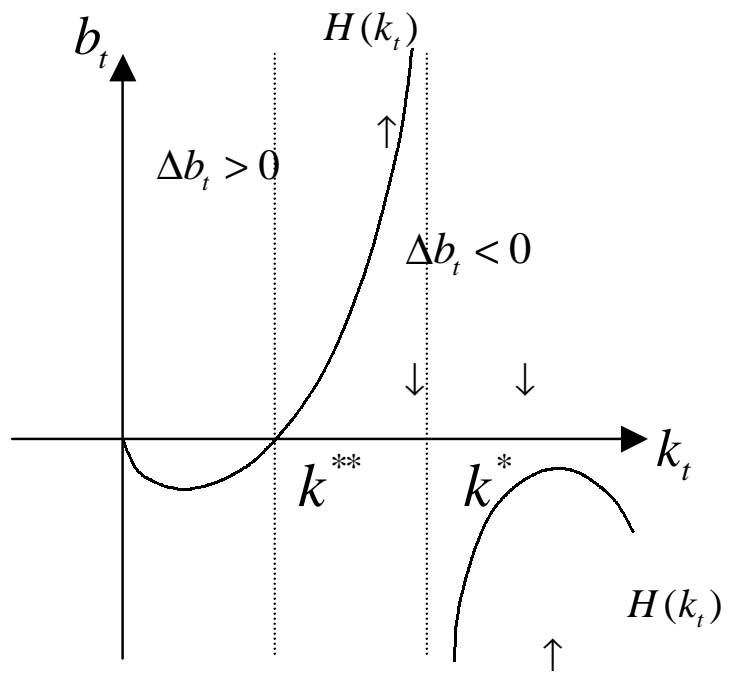

Figure $2 b: k^{*}>k^{* *}$ case 
Figure 3

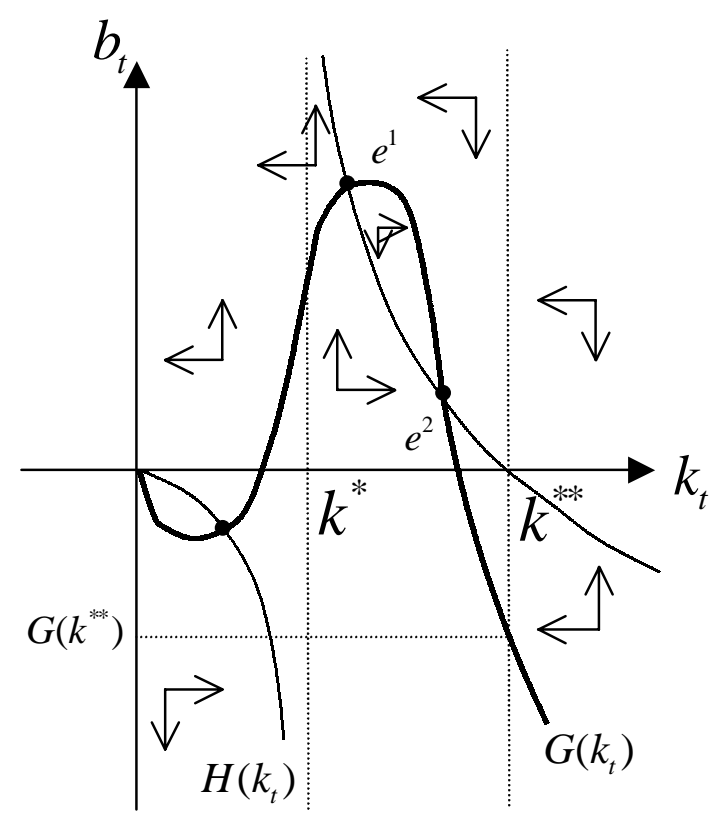

Figure $3 a: G\left(k^{* *}\right)<0$

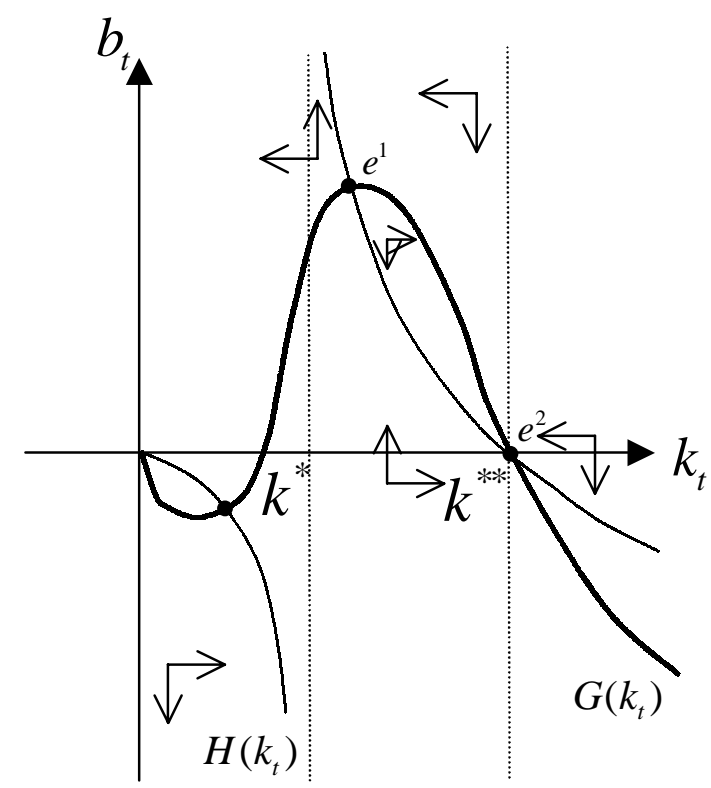

Figure $3 c: G\left(k^{* *}\right)=0$ and $G^{\prime}\left(K^{* * *}\right)<H^{\prime}\left(k^{* * *}\right)$

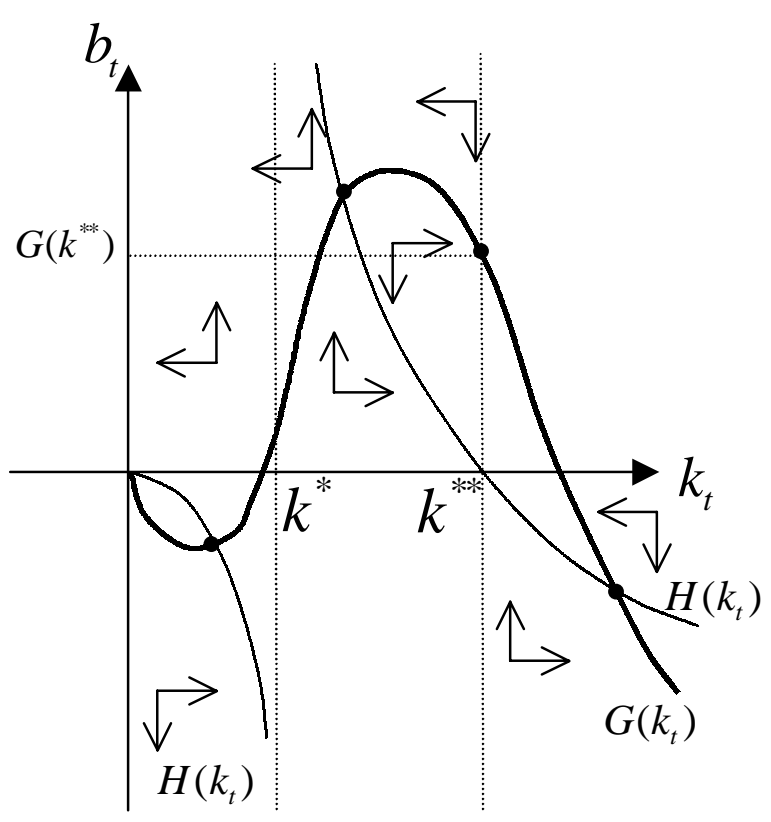

Figure $3 b: G\left(k^{* * *}\right)>0$

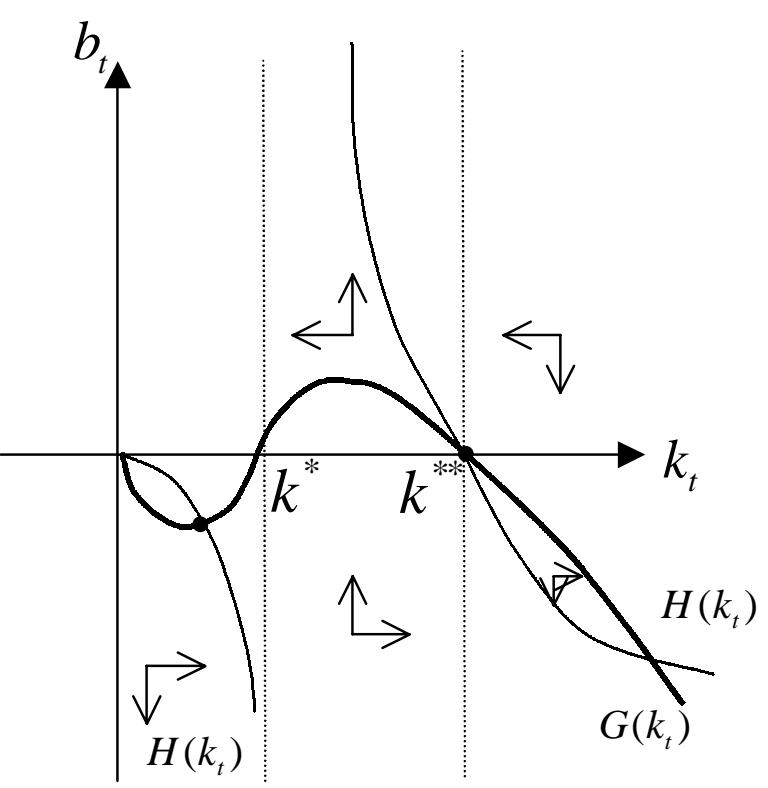

Figure $3 d: G\left(k^{* *}\right)=0$ and $G^{\prime}\left(k^{* * *}\right)>H^{\prime}\left(k^{* * *}\right)$ 
Figure 4
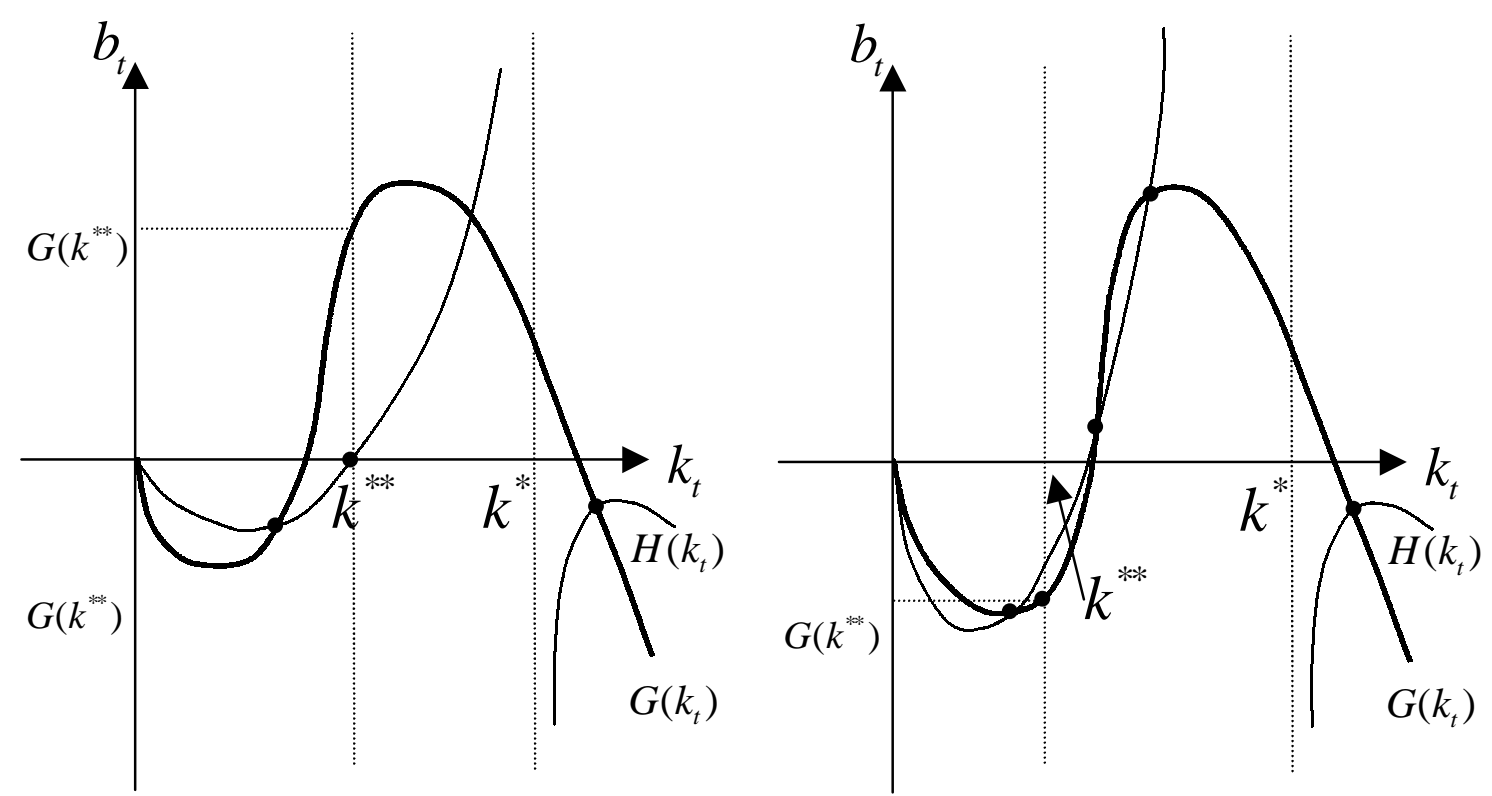

Figure $4 a: G\left(k^{* *}\right)>0$

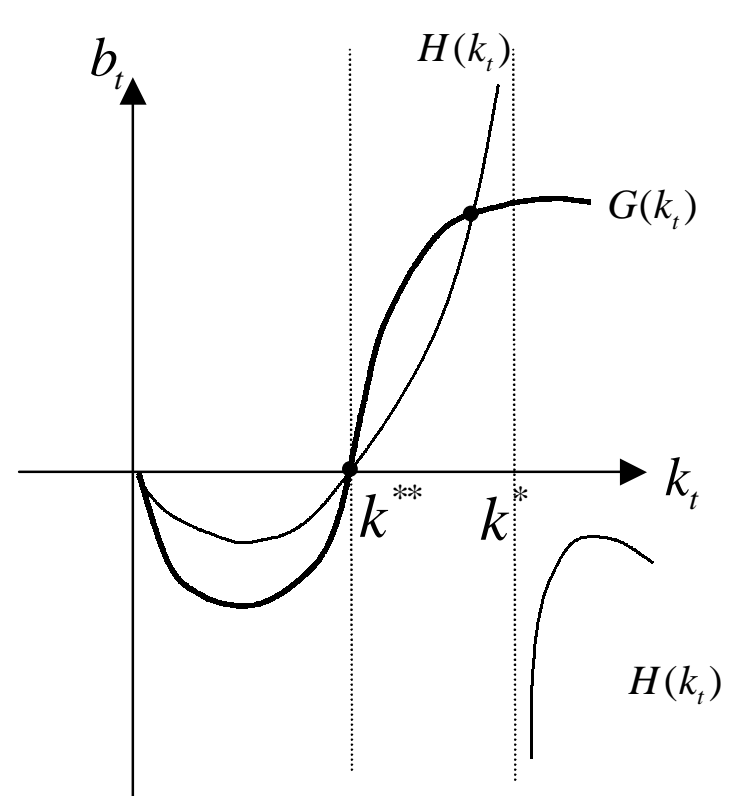

Figure $4 c: G\left(k^{* *}\right)=0$ and $G^{\prime}\left(k^{* * *}\right)>H^{\prime}\left(k^{* * *}\right)$
Figure $4 b: G\left(k^{* * *}\right)<0$

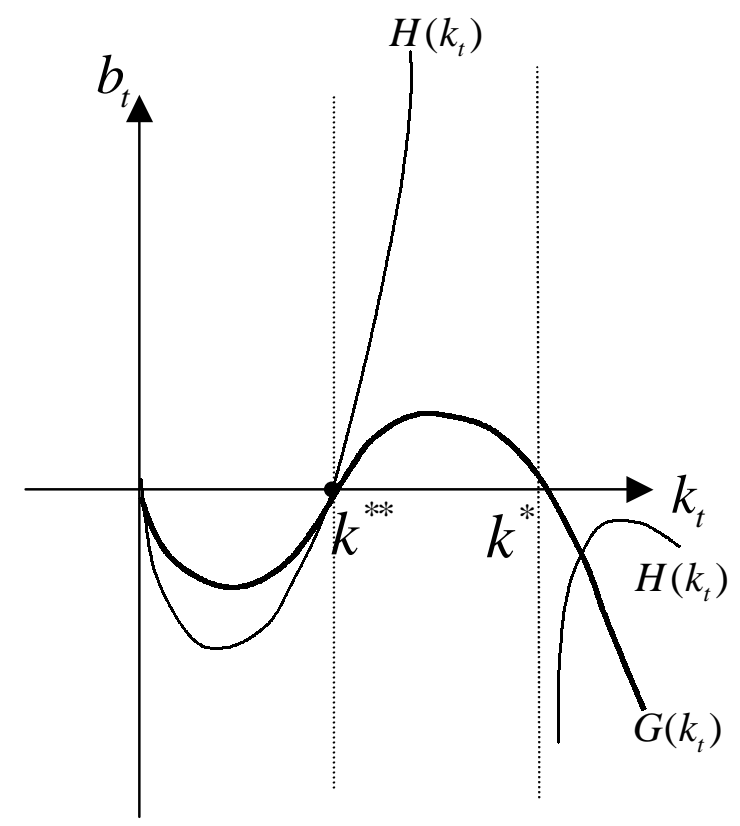

Figure $4 d: G\left(k^{* *}\right)=0$ and $G^{\prime}\left(k^{* *}\right)<H^{\prime}\left(k^{* *}\right)$ 
Figure 5

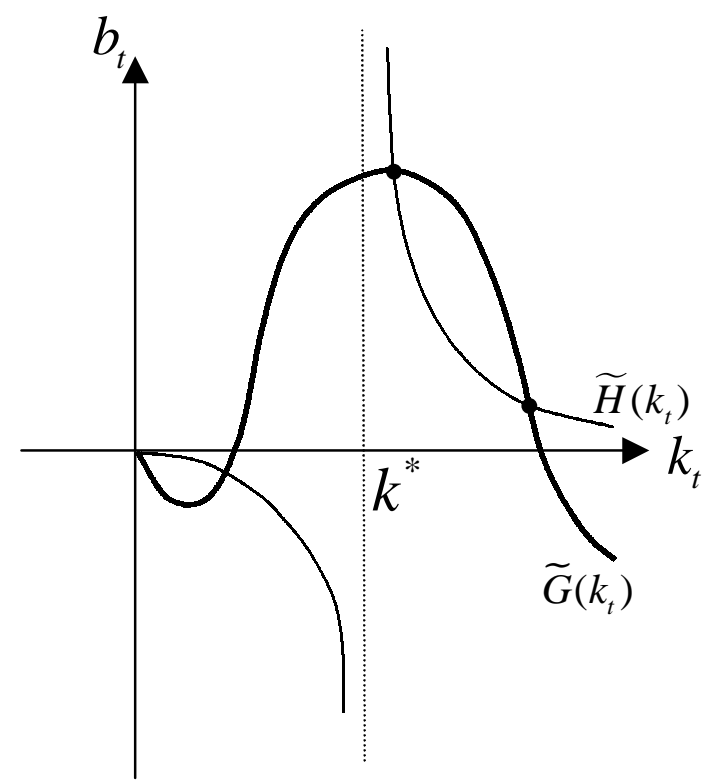

Figure $5 a: \frac{P \zeta}{1+n}>\tau^{w}$

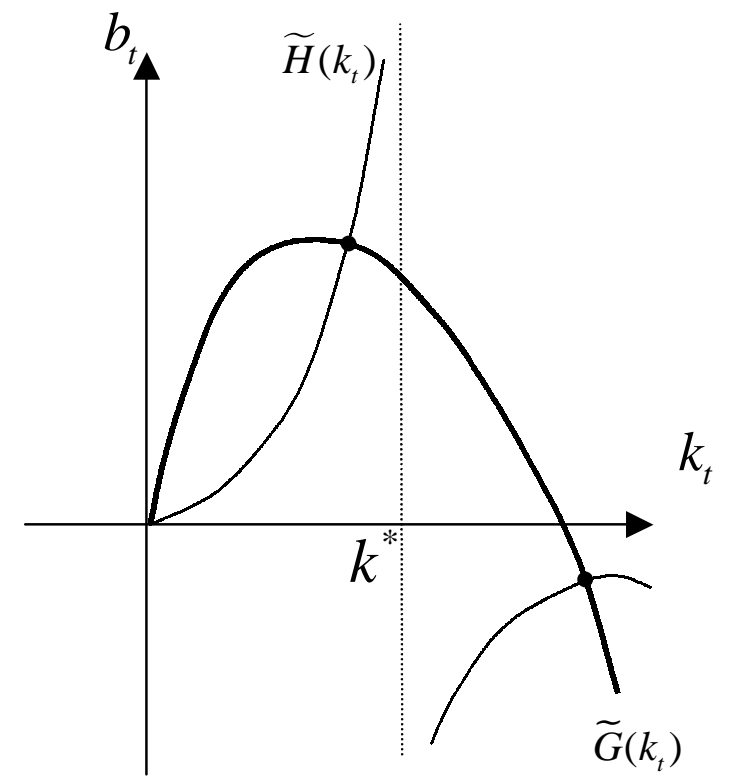

Figure $5 b: \frac{P \zeta}{1+n}<\tau^{w}$ 